\title{
Experimental investigation of the effect of injection water salinity on the displacement efficiency of miscible carbon dioxide WAG flooding in a selected carbonate reservoir
}

\author{
Abdulrazag Zekri · Hazim Al-Attar • \\ Omar Al-Farisi • Reyadh Almehaideb • \\ Essa Georges Lwisa
}

Received: 19 September 2014/ Accepted: 2 February 2015/Published online: 12 February 2015

(C) The Author(s) 2015. This article is published with open access at Springerlink.com

\begin{abstract}
The effect of injection brine salinity on the displacement efficiency of low water salinity flooding was investigated using sea water at $35,000 \mathrm{ppm}$, and two field injection waters, namely, Um-Eradhuma (UER) at $171,585 \mathrm{ppm}$ and simsima (SIM) at $243,155 \mathrm{ppm}$. The salinity of the employed waters was varied from original salinity to $1,000 \mathrm{ppm}$ and used in the displacement of oil in selected core samples. The results of this set of experiments revealed that UER salinity of 5,000 ppm is the optimum system for the candidate reservoir. UER original water and its optimum water were then used in this project as the high and low salinity waters in the $\mathrm{CO}_{2}$-WAG flooding experiments. Displacement efficiencies were evaluated under three injection modes: carbon dioxide WAG miscible flooding $\left(\mathrm{CO}_{2}-\mathrm{WAG}, 1: 1,2: 1\right.$, and 1:2), continuous $\mathrm{CO}_{2}$ injection, and waterflood. The WAG performance parameters, such as secondary and tertiary displacement efficiencies, $\mathrm{CO}_{2}$ flood utilization factor, and $\mathrm{CO}_{2}$ performance during different WAG flood cycles were determined. To insure miscibility condition between the injected gas and the employed oil, all of the flooding experiments were conducted at 3,200 psia (which is 300 psia above the minimum miscibility pressure of $\mathrm{CO}_{2}$ and used oil) and $250^{\circ} \mathrm{F}$. Experimental results indicated that core length is a critical parameter in determining the optimum WAG process, and that a minimum core length of $29 \mathrm{~cm}$ is required to insure the generation of miscibility before breakthrough in $\mathrm{CO} 2$
\end{abstract}

A. Zekri $(\bowtie) \cdot$ H. Al-Attar - R. Almehaideb · E. G. Lwisa Department of Chemical and Petroleum Engineering, United Arab Emirates University, Al Ain, UAE e-mail: a.zekri@uaeu.ac.ae

O. Al-Farisi

Subsurface Technology, Development Business Unit, ADMA-OPCO, Abu Dhabi, UAE
WAG flooding experiments. On the other hand, core length had no effect on the performance of the low salinity flooding experiments. Using single core flooding low salinity $\mathrm{CO}_{2}-$ WAG of 1:2 flooding produced an improvement in the displacement efficiency of $29 \%$ over the high salinity system. Also, composite core flooding experiments showed that the high salinity $\mathrm{CO}_{2}-2: 1 \mathrm{WAG}$ achieved a displacement efficiency of $98 \%$. These results indicate that achieving miscibility at the reservoir conditions is the dominant mechanism and that low salinity will have no major effect on the displacement efficiency of $\mathrm{CO}_{2}$-Miscible WAG flooding. Results also indicate that oil recovery during different $\mathrm{CO} 2-\mathrm{WAG}$ cycles is a function of WAG ratios.

Keywords Water salinity - Displacement efficiency · Carbon dioxide $\cdot$ Misciblle WAG $\cdot$ Carbonate reservoir

\section{Introduction}

The main goal of any enhanced oil recovery (EOR) method is to increase the capillary number thus providing "favorable" mobility ratios $(M<1.0)$. The capillary number (Abrams 1975 ) is defined as the ratio of viscous to capillary forces.

$N_{\text {ca }}=\frac{\text { Viscous forces }}{\text { Capillary forces }}=\frac{v \mu}{\sigma \cos \theta}$

where $v$ and $\mu$ are the velocity and viscosity, respectively of the displacing fluid, $\sigma$ is the oil-water interfacial tension and $\theta$ is the contact angle between the oil-water interface and the rock surface measured between the rock surface and the denser phase (water in this case).

The mobility ratio, $M$, is defined (Craig et al. 1955) as the ratio of mobility of the displacing fluid to that of the displaced fluid. 
$M=\frac{(k / \mu)_{\text {Displacing }}}{(k / \mu)_{\text {Displaced }}}$

where $k$ is the relative or effective permeability.

The overall efficiency of any EOR process depends on both the microscopic and macroscopic sweep efficiencies. While the fluids density difference and rock heterogeneity affect the macroscopic efficiency, the microscopic displacement efficiency is influenced by the interfacial interactions involving interfacial tension and dynamic contact angles.

Miscible gas injection is the second largest process in enhanced oil recovery processes today (Hinderaker et al. 1996). Displacement efficiencies' between 90 and $98 \%$ are the criteria adopted by the oil industry in assessing the miscibility conditions of slim tube experiments (Stalkup 1992). Carbon dioxide miscibility achieved through multicontact process (Stalkup 1992) which require a certain core length depending on the injection rate. The residual oil saturations in gas swept zones have been found to be quite low. However, the volumetric sweep of the flood has always been a cause of concern. The mobility ratio, which controls the volumetric sweep, between the injected gas and displaced oil bank in gas processes, is typically highly unfavorable due to the relatively low viscosity of the injected phase. This difference makes mobility and consequently flood profile control the biggest concern for the successful application of this process.

The above concern has led to the development of the water-alternating-gas (WAG) process for flood profile control. The higher microscopic displacement efficiency of gas combined with the better macroscopic sweep efficiency of water has been found to significantly increase the incremental oil production over the plain waterflood. The WAG process was first proposed by Caudle and Dyes 1958 and has remained the industry default mobility control method for gas injection, mainly due to the lack of proven flood profile control alternatives. Reservoir key parameters such as wettability, interfacial tension, connate water saturation, gravity segregation, and the reservoir heterrogeneity could add complexity to the design of a successful WAG flood.

Christensen et al. (1998) showed that this process has been applied to rocks from very low permeability chalk up to high permeability sandstone. Most of the applied processes were miscible. The miscibility issue is generally based on gas availability, but is mainly reported as an economic consideration and the extent of reservoir repressurization required for process application. The major design issues for WAG are reservoir characteristics and heterogeneity, rock and fluid characteristics, composition of injection gas, injection pattern, WAG ratio, three-phase relative permeability effects and flow dispersion. It is important to note that plain gas injection is considered as a part of WAG process with a WAG ratio of $0: 1$, hence the design issues pertinent to WAG are applicable to plain gas injection as well.

Stratification and heterogeneities strongly influence the oil recovery process. Reservoirs with higher vertical permeability are influenced by cross flow perpendicular to the bulk flow direction. Viscous, capillary, gravity and dispersive forces generally influence this phenomenon ${ }^{5}$. Cross-flow may influence the vertical sweep increase, but generally the effects are detrimental to oil recoverymainly due to the gravity segregation and decreased flow velocity in the reservoir. This leads to reduced frontal advancement in lower permeability layer. WAG recoveries and continuous gas injections are more strongly affected by these phenomena. Reservoir heterogeneity controls the injection and sweep patterns in the flood. The reservoir simulation studies ${ }^{5}$ for various $\mathrm{k}_{\mathrm{v}} / \mathrm{k}_{\mathrm{h}}$ (vertical to horizontal permeability) ratios suggest that higher ratios adversely affect oil recovery in WAG process.

Fluid characteristics are generally black-oil or compositional PVT properties obtained in the laboratory by standardized procedures (Rogers and Grigg 2000). Very accurate determination of fluid properties can be obtained with current techniques. However, rock-fluid interactions such as adhesion, spreading and wettability affect the displacement in the reservoir. In reservoir simulators, rockfluid interactions are generally lumped into one parameter-relative permeability. The relative permeability is the connecting link between the phase behavior and transport properties of the system. Relative permeability is an important petrophysical parameter, as well as a critical input parameter in predictive simulation of miscible floods. Relative permeability data are generally measured in the laboratory by standardized procedures with actual reservoir fluids and cores and at reservoir conditions (Rogers and Grigg 2000).

The optimum WAG ratio is influenced by the wetting state of the rock (Zekri and Natuh 1992; Jackson et al. 1985). WAG ratio of 1:1 is the most popular for field applications (Christensen et al. 1998). However, gravity forces dominate water-wet tertiary floods while viscous fingering controls oil-wet tertiary floods. High WAG ratios have a large effect on oil recovery in water-wet rocks resulting in lower oil recoveries. Tertiary $\mathrm{CO}_{2}$ floods controlled by viscous fingering had a maximum recovery at WAG ratio of about 1:1. Floods dominated by gravity tonguing showed maximum recovery with the continuous $\mathrm{CO}_{2}$ slug process. The optimum WAG ratio in secondary floods was a function of the total $\mathrm{CO}_{2}$ slug size (Jackson et al. 1985).

The properties of the injected water make another parameter that have a major effect on the level of incremental 
WAG recovery. Kulkarni and Rao (2005) presented the first work in the area of combination of LSW and WAG. They studied the effect of changing the injected water composition on oil recovery during WAG and tertiary continuous gas injection CGI using model oil and sandstone formation. They found that CGI is insensitive to water composition. They reported a decrease in ultimate WAG recovery with decreasing water salinity due to increasing $\mathrm{CO}_{2}$ water solubility. Aguilera and de Ramos (2004) studied $\mathrm{CO}_{2^{-}}$ water-hydrocarbon system behavior and they measured IFTs and surface tensions. They concluded that $\mathrm{CO}_{2}$ diffuses first through water then through hydrocarbon and promotes swelling. Aleidan and Mamora (2010) concluded that lowering water salinity (increasing $\mathrm{CO}_{2}$ solubility in water) resulted in higher oil recovery during $\mathrm{WACO}_{2}$ and simultaneous $\mathrm{CO}_{2}$-water injection process $\mathrm{SWACO}_{2}$. They reported that oil recovery could be increased by as much as $18 \%$ with low salinity flooding. They attributed that to the better displacement efficiency offered by $\mathrm{CO}_{2}-$ water mixture which will contact the bypassed oil after the $\mathrm{CO}_{2}$ slug. Jiang et al. (2010) used two oils model oil (mixing n-decane with an equal weight of n-hexadecane) and crude oil from cottonwood creek oil field to study the effect of water salinity on the $\mathrm{CO}_{2}$ tertiary WAG process. They concluded that brine salinity has no influence on water flooding recovery in the case of model oil; and that divalent ion in the injection brine does not have any influence on the result either. On the other hand, the secondary recovery of water flooding decreases with the increase of injection brine salinity in the experiments with Cottonwood Creek crude oil. Dang et al. (2013) conducted a reservoir simulation on LSW $\mathrm{CO}_{2}$ four cycles WAG 1:1 and reported a $9 \%$ increase of the OOIP recovery by LSW over high salinity water. To our knowledge very limited work has been reported in the literature that covers the influence of injection brine salinity on $\mathrm{CO}_{2}$ WAG process and additional work is needed. In this work, the effect of salinity of the injection brine on WAG performance in secondary miscible $\mathrm{CO}_{2}$ WAG flooding is studied through core flood experiments using actual carbonate cores and reservoir fluids. An overall plan was developed by joint group representing ADNOC group companies and UAEU EOR research team as presented in Fig. 1.

\section{Experimental materials and setup}

Materials

Reservoir crude oil from BU field was used in all experiments. The oil was filtered through a $5.0 \mu \mathrm{m}$ filter paper (with a vacuum pump) to remove any possible solid particles. The oil is sweet oil that has no $\mathrm{H}_{2} \mathrm{~S}$ and about
$2.6 \mathrm{~mol} \% \mathrm{CO}_{2}$ which is very low. The oil API gravity and viscosity are 35 and $3.08 \mathrm{cp}$ measured at room temperature $\left(25^{\circ} \mathrm{C}\right)$, respectively. Formation brine (FB) (163,000 ppm), Um-Eradhuma (URD) (171,585 ppm), simisema (SIM) $(209,988 \mathrm{ppm})$, and sea water (SW) $(34,980 \mathrm{ppm})$ were used to determine the optimum salinity system for the oil recovery of the candidate reservoir. Table 1 shows the analysis of these water samples.

\section{Core samples}

Forty-six core samples were obtained from well BU 589 and their corresponding depths, and measured permeabilities, porosities, and mean pore sizes are presented in Table 2. Twelve core samples representing different well depths were selected for mineralogical analysis using an X-ray diffraction (Philips X-ray diffracto-meter model PW/ 1840). The objective of the analysis was to make sure that rock typing should be considered in the preparation of composite cores. The results of the analysis indicated that there was no mineralogy variation in well B589 as presented in Table 3. Thirteen secondary single core (SC) water flooding tests were conducted to determine the optimum salinity system. Six CC samples were prepared using cores representing various core categories as shown in Table 4. All of the CCs were arranged in a random order with an overall average permeability equal to well BU 589 average permeability of $20 \mathrm{md}$ and length of $32 \mathrm{~cm}$. The cores were cleaned and saturated with oil at connate water saturation employing the current industry standard procedure. The carbonate cores used for the tests were aged in oil for 14 days, to restore their original wettability. Actual oil sample from Abu Dhabi BU field of interest was used as the oleic phase in all of the experiments and standard cleaning procedures were implemented between various displacements.

\section{Experimental setup}

Core flooding system which operates under reservoir conditions with miscible gas module XRFS-150 was used in this project. The system is configured for liquid/liquid displacements under unsteady state or steady state conditions and with the addition of the $\mathrm{CO}_{2}$ delivery system allows miscible flood experiments to be performed. The system is rated to 10,000 psig confining pressure and 9,000 psig pore pressure at $300{ }^{\circ} \mathrm{F}$ temperature.

The system features automated data acquisition, manual and semi-automated operation via a Windows based graphical interface as shown in Fig. 2. Single and CC experiments were conducted in this project. Seven types of 


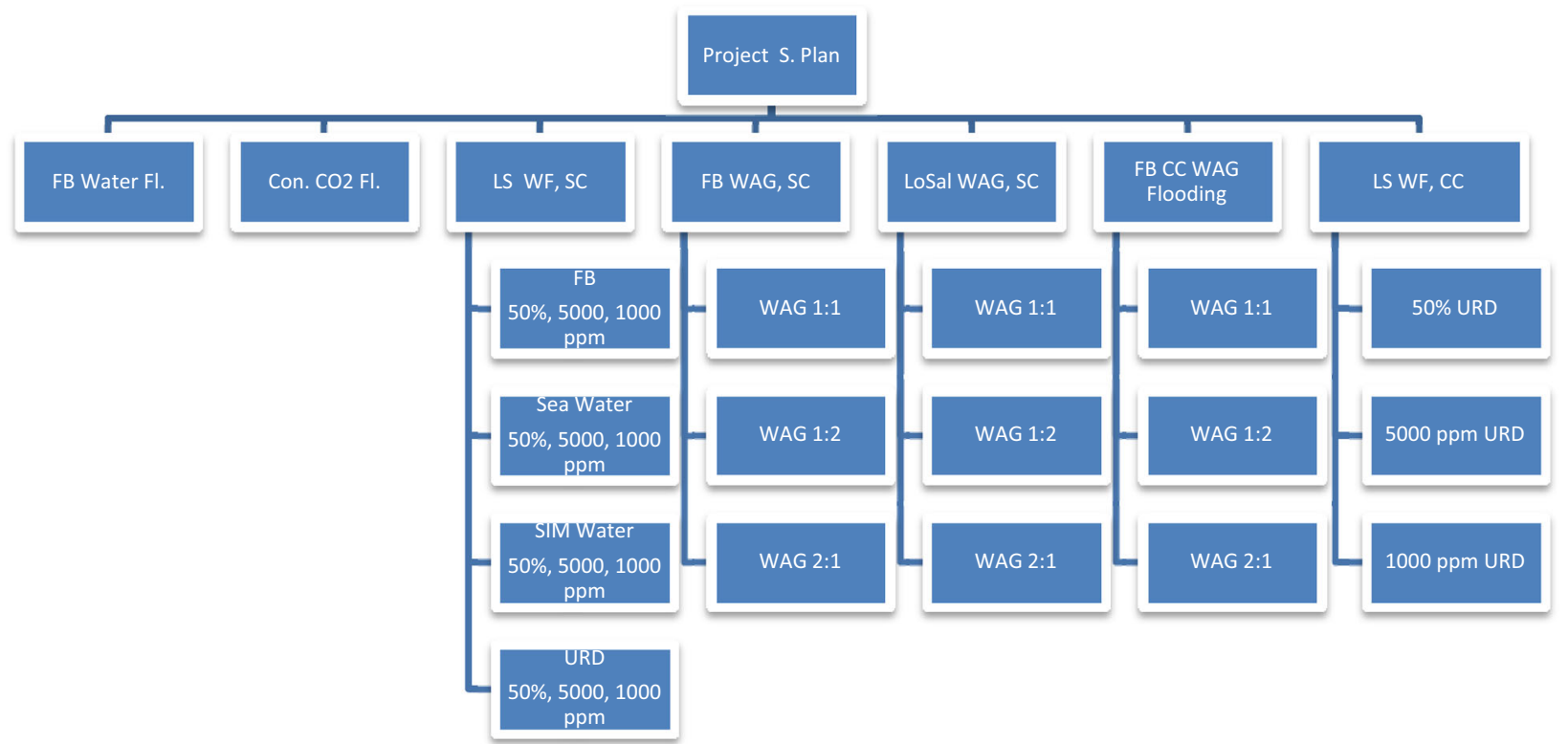

$\mathrm{SW}=$ sea water, $\mathrm{URD}=$ Eradhuma water, $\mathrm{SIM}$ water $=$ Simisema, $\mathrm{SC}=$ single core, $\mathrm{CC}=$ composite core, $\mathrm{FB}=$ formation brine $, \mathrm{Con} .=\mathrm{continues}, \mathrm{Fl}=$ flooding, $\mathrm{LS}=$ low salinity,

Fig. 1 Block diagram showing the various experimental runs performed in the project

Table 1 Analysis of the water samples

\begin{tabular}{|c|c|c|c|c|c|c|c|c|c|}
\hline \multirow[t]{2}{*}{ Type } & \multicolumn{8}{|l|}{ Mg/L } & \multirow[t]{2}{*}{ TDS salinity (ppm) } \\
\hline & $\mathrm{Ca}^{++}$ & $\mathbf{K}$ & $\mathrm{Mg}^{++}$ & $\mathrm{Na}^{+}$ & $\mathrm{Fe}^{+++}$ & $\mathrm{HCO}_{3}^{-}$ & $\mathrm{Cl}^{-}$ & $\mathrm{SO}_{4}^{-}$ & \\
\hline SIM & 17,969 & - & 2,631 & 58,907 & - & 103 & 130,066 & 302 & 209,988 \\
\hline UER & 12,200 & - & 2,629 & 50,089 & - & 212 & 106,088 & 366 & 171,585 \\
\hline SW & 600 & - & 1,560 & 13,900 & & 200 & 24,300 & 420 & 34,980 \\
\hline Formation water & 14,337 & & 1,149 & 46,450 & 248 & 351 & 100,220 & 245 & 163,000 \\
\hline
\end{tabular}

experiments were performed in the present study. These include continuous $\mathrm{CO}_{2}$ gas injection $\mathrm{CCI}$, high salinity single core water flooding HSSC, low salinity single core water flooding LSSC, high salinity composite core flooding HSCC, low salinity composite core flooding LSCC, high salinity single core $\mathrm{CO}_{2}$ WAG injection LSSC-WAG, and high salinity $\mathrm{CC} C \mathrm{C} 2-\mathrm{WAG}$ injection HSCC WAG. All cores were saturated with formation brine solution after core cleaning to determine pore volume and absolute permeability. They were then brought to connate water saturation by flooding with crude oil at high flow rate (160 cc/hr). All of the experiments consisted of the following steps: saturation with formation brine at reservoir conditions, determination of pore volume and absolute permeability, oil flood to connate water saturation, and end point oil-permeability. $\mathrm{CO} 2-\mathrm{WAG}$ injection, continuous $\mathrm{CO}_{2}$, or water injection tests were then conducted after the establishments of connate water saturations in secondary flooding mode. All tests were conducted at reservoir conditions of $250{ }^{\circ} \mathrm{F}$ and 3,200 psia pressure. The employed pressure was 300 psia above the minimum miscibility pressure of the studied system. An overburden pressure of 4,000 psia and a constant flooding rate of $1 \mathrm{cc} /$ sec were used in all of the runs. During the secondary water flooding and WAG flooding, the injected fluid volumes, the pressure drop across the core, and the produced oil/water/ and gas volumes were continuously measured. In addition to that oil recovery, residual oil saturation, displacement efficiency was measured for the studied system.

\section{Results and discussion}

The objectives of the above tests were to determine the effects of the gas injection mode (CCGI or WAG), WAG ratio, WAG timing, length of the system, and WAG brine salinity on the dynamic displacement tests in selected actual carbonate cores from UAE. 
Table 2 Properties of the cores used in this work

\begin{tabular}{|c|c|c|c|c|c|c|c|c|c|c|c|}
\hline Catg. & No. & Depth (ft) & $\mathrm{R}$ mean (microns) & $\mathrm{Kw}(\mathrm{mD})$ & Porosity (\%.) & Catg. & No. & Depth (ft) & $\mathrm{R}$ mean (microns) & $\mathrm{Kw}(\mathrm{m} \mathrm{D})$ & Porosity (\%) \\
\hline \multirow[t]{3}{*}{ X } & 3 & 8647.70 & 0.6137 & 19.8400 & 13.5766 & \multirow[t]{10}{*}{$\mathrm{C}$} & 12 & 8657.20 & 0.6603 & 11.1060 & 25.5009 \\
\hline & 47 & 8702.10 & 0.4524 & 6.7780 & 14.3530 & & 14 & 8659.30 & $0 .+273$ & 24.1010 & $24.665+$ \\
\hline & 46 & 8701.80 & NPP & 8.8280 & 15.3111 & & 15 & 8660.90 & 0.3312 & 27.3250 & 225.5573 \\
\hline \multirow[t]{11}{*}{ A } & 8 & 8653.60 & 0.4989 & 8.6570 & 21.5579 & & 17 & 8662.90 & 0.6651 & $22.3-10$ & 27.002 \\
\hline & 9 & 8654.40 & 0.6275 & 6.2720 & 21.0851 & & 18 & 8663.90 & NPP & 23.7610 & 28.4792 \\
\hline & 10 & 8655.20 & 0.3621 & 8.8710 & 21.4155 & & 29 & 8677.30 & 0.7774 & 31.2640 & 28.2615 \\
\hline & 16 & 8661.90 & 0.3041 & 8.0830 & 24.2622 & & 33 & 8688.80 & 0.4637 & 16.5510 & 25.7829 \\
\hline & 30 & 8685.70 & 0.4685 & 8.3480 & 24.4753 & & 36 & 3691.30 & 0.3593 & $10 .-930$ & 2.1555 \\
\hline & 38 & 8693.70 & 0.4105 & 8.4380 & 23.9118 & & 37 & 3692.30 & $0 .-503$ & 20.1020 & 25.3911 \\
\hline & 40 & 8695.10 & 0.3038 & 8.5010 & 23.6913 & & 39 & 8694.90 & 0.4262 & 11.6970 & 2.S232 \\
\hline & 41 & 8696.80 & 0.2676 & 8.7380 & 23.5378 & \multirow[t]{6}{*}{$\mathrm{D}$} & 5 & 8650.80 & 1.0845 & 32.6960 & 23.5448 \\
\hline & 42 & 8697.30 & 0.4209 & 8.7190 & 23.6682 & & 7 & 8652.20 & 0.3595 & 45.6930 & 23.531 \\
\hline & 43 & 8698.30 & 0.2754 & 9.8410 & 23.1483 & & 19 & 8664.20 & 1.1130 & 53.1260 & 27.5623 \\
\hline & 44 & 8699.40 & 0.2653 & 6.1780 & 22.7712 & & 20 & 8665.80 & 0.7485 & 73.790 & 27.5992 \\
\hline \multirow[t]{11}{*}{ B } & 1 & 8644.20 & 0.7736 & 19.4890 & 18.7331 & & 26 & 8672.10 & NPP & 45.2880 & 26.4881 \\
\hline & 2 & 8645.90 & 0.6385 & 15.5140 & 21.0039 & & 28 & 3674.80 & 0.7085 & 59.3260 & 23.2627 \\
\hline & 4 & 8648.10 & 0.6983 & 22.4870 & 19.6169 & \multirow[t]{9}{*}{$\mathrm{E}$} & 21 & 8666.90 & 0.7236 & 120.0800 & 27.0443 \\
\hline & 6 & 8648.30 & 0.5357 & 18.0520 & 19.5563 & & 22 & 8667.60 & 0.7491 & 130.3900 & 2.0560 \\
\hline & 11 & 8656.20 & 1.1176 & 13.7040 & 24.2714 & & 23 & 8668.20 & 0.365 & 96.9340 & $25 .-92$ \\
\hline & 13 & 8658.30 & 0.3311 & 20.0050 & 20.6196 & & 24 & 8669.90 & 0.7865 & 96.9840 & 25.4492 \\
\hline & 31 & 8686.90 & 0.4656 & 13.0550 & 23.9559 & & 25 & 8670.30 & 1.2285 & 129.9890 & 28.5689 \\
\hline & 32 & 8687.30 & NPP & 14.6090 & 24.1714 & & 25 & 3670.30 & 1.2235 & 129.9390 & 23.5639 \\
\hline & 34 & 8689.10 & 0.5980 & 14.2430 & 23.3993 & & 27 & 3673.70 & 0.6320 & 93.3770 & 23.6762 \\
\hline & 35 & 8690.90 & 0.4476 & 10.2340 & 23.1979 & & & & & & \\
\hline & 45 & 8700.70 & NPP & 14.7010 & 22.8542 & & & & & & \\
\hline
\end{tabular}

Table 3 Mineralogical analysis of selected cores

\begin{tabular}{lllll}
\hline No. & Depths & Major & Subordinate & Minor \\
\hline 2 & 8645.9 & Calcite $\left(\mathrm{CaCO}_{3}\right)$ & - & Dolomite $\left[\mathrm{CaMg}\left(\mathrm{CO}_{3}\right)_{2}\right]$ \\
6 & 8651.3 & Calcite $(\mathrm{CaCO})$ & - & Dolomite $\left[\mathrm{CaMg}\left(\mathrm{CO}_{3}\right)_{2}\right]$ \\
10 & 8655.2 & Calcite $\left(\mathrm{CaCO}_{3}\right)$ & - & - \\
14 & 8659.3 & Calcite $\left(\mathrm{CaCO}_{3}\right)$ & - & Dolomite $\left[\mathrm{CaMg}\left(\mathrm{CO}_{3}\right)_{2}\right]$ \\
18 & 8663.9 & Calcite $\left(\mathrm{CaCO}_{3}\right)$ & - & Dolomite $\left[\mathrm{CaMg}\left(\mathrm{CO}_{3}\right)_{2}\right]$ \\
22 & 8664.6 & Calcite $\left(\mathrm{CaCO}_{3}\right)$ & - & \\
26 & 8672.1 & Calcite $\left(\mathrm{CaCO}_{3}\right)$ & - & \\
32 & 8687.3 & Calcite $\left(\mathrm{CaCO}_{3}\right)$ & - & \\
36 & 8691.3 & Calcite $\left(\mathrm{CaCO}_{3}\right)$ & - & \\
42 & 8697.3 & Calcite $\left(\mathrm{CaCO}_{3}\right)$ & - & Quartz: $\left.(\mathrm{SiO})_{2}\right)$, amphibole, clay minerals \\
44 & 8699.4 & Calcite $\left(\mathrm{CaCO}_{3}\right)$ & Kaolinite & Kaolinite, quartz $\left(\mathrm{SiO}_{2}\right)$ \\
46 & 8701.8 & Calcite $\left(\mathrm{CaCO}_{3}\right)$ & - & \\
\hline
\end{tabular}

Optimization of low salinity

To evaluate the effect of different water types and their salinities on the recovery and to determine the optimum low salinity system, thirteen secondary core flooding tests were conducted. The tested waters were UER brine $(171,585 \mathrm{ppm}), \quad$ SIM brine $(209,988 \mathrm{ppm}), \quad$ SW
(34,980 ppm), and formation brine $(163,000 \mathrm{ppm})$. The employed waters were diluted to one half its original salinity, 5,000, and 1,000 ppm. All these experiments were conducted at the same conditions of injection rate of $1 \mathrm{cc} /$ sec, pressure of 3,200 psia, temperature of $250^{\circ} \mathrm{F}$, using single cores (SC) of similar permeabilites obtained from the same well BU 589. The current industry procedures 
Table 4 Composite cores

\begin{tabular}{|c|c|c|c|c|}
\hline Composite core no. & Sample no. & $L(\mathrm{~cm})$ & $\mathrm{Kw}(\mathrm{md})$ & Porosity (\%) \\
\hline \multirow[t]{5}{*}{ A } & $6 \mathrm{~A}$ & 6.918 & 18.1 & 20.53 \\
\hline & $22 \mathrm{~A}$ & 4.766 & 23.4 & 24.44 \\
\hline & $24 \mathrm{~A}$ & 6.497 & 48.7 & 25.13 \\
\hline & $30 \mathrm{~A}$ & 6.421 & 8.3 & 24.45 \\
\hline & $36 \mathrm{~A}$ & 6.913 & 10.5 & 24.06 \\
\hline \multirow[t]{5}{*}{ B } & $16 \mathrm{~A}$ & 6.067 & 8.1 & 26.11 \\
\hline & $18 \mathrm{~A}$ & 7.323 & 28.8 & 27.32 \\
\hline & $28 \mathrm{~A}$ & 5.023 & 59.3 & 25.45 \\
\hline & $34 \mathrm{~A}$ & 4.587 & 14.2 & 23.53 \\
\hline & $46 \mathrm{~A}$ & 8.223 & 8.8 & 18.76 \\
\hline \multirow[t]{5}{*}{$\mathrm{D}$} & $14 \mathrm{~A}$ & 6.679 & 24.1 & 21.79 \\
\hline & $20 \mathrm{~A}$ & 5.117 & 30.2 & 25.19 \\
\hline & $26 \mathrm{~A}$ & 6.251 & 45.3 & 26.01 \\
\hline & $32 \mathrm{~A}$ & 6.306 & 14.6 & 24 \\
\hline & $40 \mathrm{~A}$ & 7.796 & 8.5 & 22.37 \\
\hline \multirow[t]{5}{*}{$\mathrm{E}$} & 7 & 7.255 & 19.04 & 22.3 \\
\hline & 24 & 6.404 & 32.44 & 26 \\
\hline & 36 & 6.051 & 4.372 & 25.69 \\
\hline & 20 & 6.532 & 30.748 & 26.34 \\
\hline & 23 & 6.582 & 40.41 & 21.63 \\
\hline \multirow[t]{5}{*}{$\mathrm{F}$} & 19 & 7.161 & 53.126 & 27.37 \\
\hline & 28 & 7.174 & 59.326 & 28.07 \\
\hline & 41 & 7.08 & 8.738 & 23.37 \\
\hline & 42 & 7.247 & 8.719 & 23.5 \\
\hline & 47 & 7.16 & 6.778 & 14.26 \\
\hline \multirow[t]{4}{*}{$\mathrm{G}$} & 3 & 7.364 & 19.84 & 13.48 \\
\hline & 13 & 7.132 & 20.005 & 20.48 \\
\hline & 14 & 5.871 & 24.101 & 24.49 \\
\hline & 18 & 7.1 & 28.761 & 28.28 \\
\hline
\end{tabular}

were followed in the core preparation and secondary flooding experiments. The flooding results of these set of experiments are presented as oil recovery percent of original oil in place (OOIP) versus type of brine as shown in Fig. 3.

Figure 3 shows that the highest oil recovery of $84.5 \%$ of the OOIP was obtained with the 5,000 ppm dilution. Formation brine yielded the lowest oil recovery of $48.1 \%$ of the OOIP. Reduction of UER water salinity below 5,000 ppm did not improve the displacement efficiency of the process but resulted in a reduction of overall oil recovery. The results also indicated that the $5,000 \mathrm{ppm}$ salinity seems to be the optimum salinity for all of the employed waters in this study. Therefore, URE 5,000 ppm salinity will be referred to as low salinity water and UER 171,585 ppm as high-salinity water in the evaluation of carbon dioxide water altering gas process $\mathrm{CO} 2-\mathrm{WAG}$ evaluation and other water flooding experiments in this project.

Comparison between continuous $\mathrm{CO}_{2} \mathrm{CCI}$ and high and low salinity injection

Four experiments were conducted using single cores with similar permeability of $11 \mathrm{md}$ to assess the effect of continuous $\mathrm{CO}_{2}$ injection $\mathrm{CCI}$, high salinity water flooding (HSWF SC, 171,585 ppm), and low salinity water flooding (LSWF SC, 5,000 ppm) on the displacement efficiency of the studied system. The $\mathrm{CO}_{2}$ injection experiments were conducted at pressure of 3,200 psia (300 psia above the minimum miscibility pressure MMP) to insure the prevailing of miscibility conditions. The experimental runs were conducted in a secondary mode, i.e., at connate water saturation. Pressure drop, oil, water and gas production
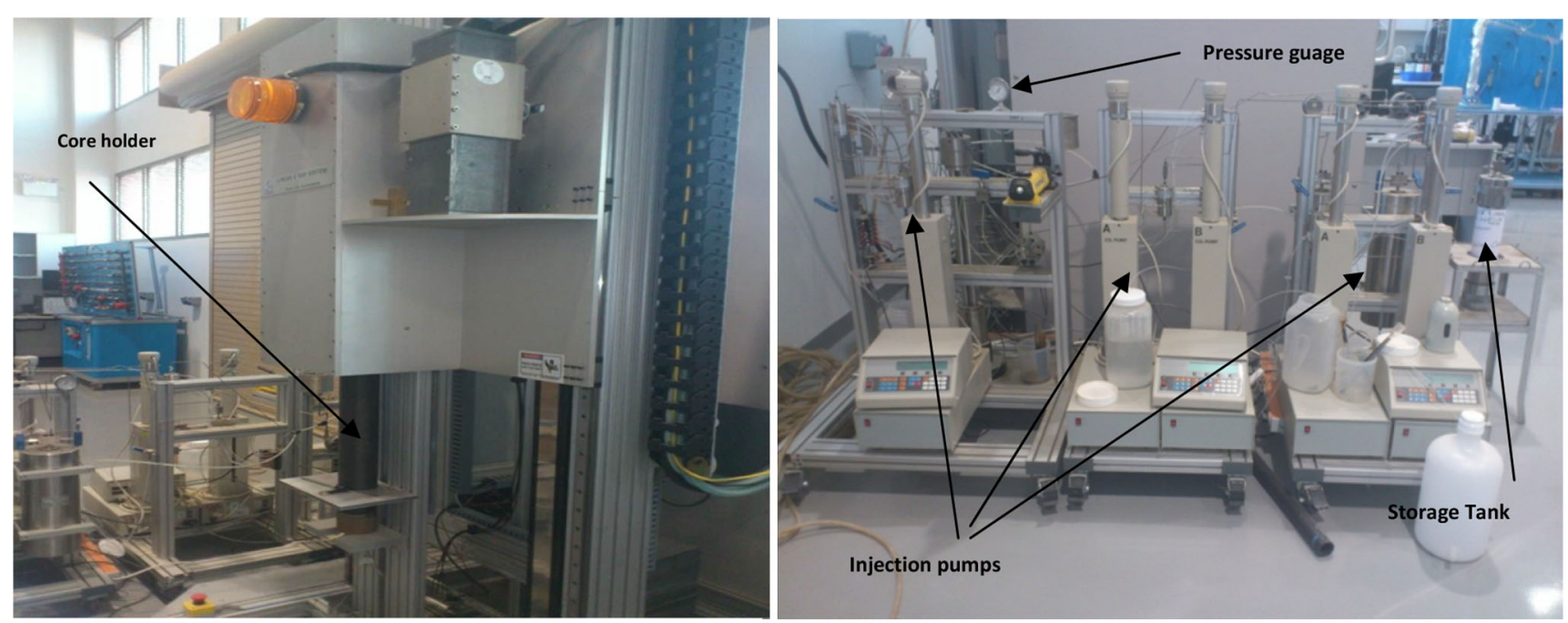

Fig. 2 A photograph of the core flooding system 
Fig. 3 Oil recovery versus water type with different salinity concentrations

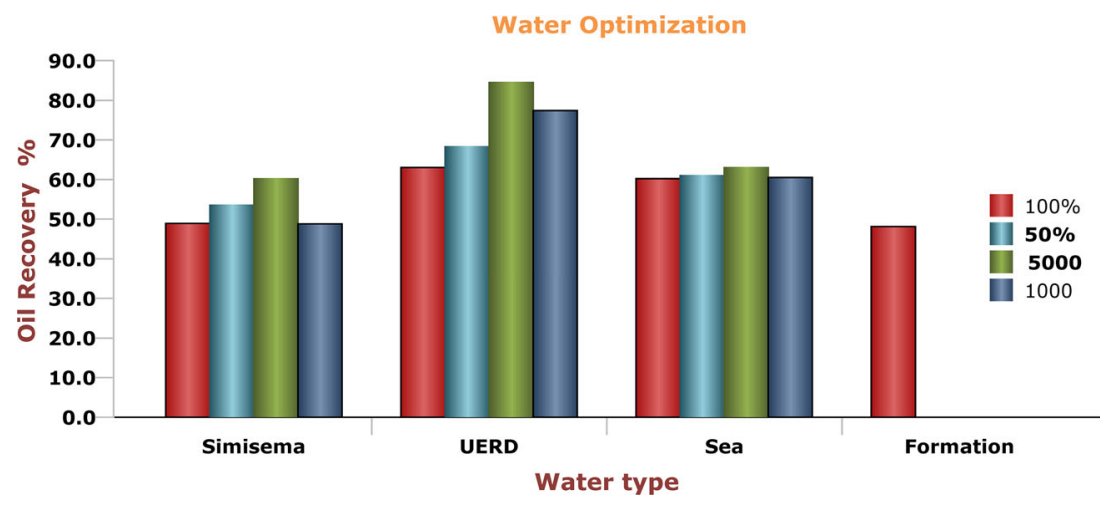

were continuously monitored as function of pore volume injected. Injection rates were kept constant in all runs at $1 \mathrm{cc} / \mathrm{sec}$. Figure 4 shows the effect of injection brine salinity on the oil recovery for UER $100 \%, 5,000 \mathrm{ppm}$, formation brine, and CCI, respectively.

The low salinity UER 5,000 ppm water flooding shows the highest oil recovery of $84.5 \%$ of the oil in place after injection of about 5 pore volumes of water. Continuous $\mathrm{CO}_{2}$ injection yields around $73.5 \%$ of OOIP. The low oil recovery of CCI is attributed to the core length effect on the performance of $\mathrm{CO}_{2}$ injection. In the $\mathrm{CCI}$ a core length of $7.5 \mathrm{~cm}$ was used, which is shorter than the required length to achieve miscibility. This issue will be discussed in details in the effect of core lengths on the WAG performance section.

\section{Degraded salinity flooding}

A high salinity injection followed by low salinity injection experiment was conducted to evaluate the effect of low salinity injection on oil recovery as a tertiary stage. A CC sample with an average permeability of $21.55 \mathrm{md}$ and porosity of $23.72 \%$ was used in this run. UER water of salinity of $171,585 \mathrm{ppm}$ followed by URE diluted to $80,000,5,000$, and $1,000 \mathrm{ppm}$ test was performed. The test was conducted at reservoir conditions of 3,200 psia and $250{ }^{\circ} \mathrm{F}$ with an injection rate of $1 \mathrm{cc} / \mathrm{sec}$. Oil recovery obtained by the degraded salinity flooding (DSF) is shown in Fig. 5. It can be observed that the injection of low salinity brine in tertiary mode has increased the incremental oil recovery. About $64.12 \%$ of OOIP was recovered by injection of high salinity brine i.e., UER water of $171,585 \mathrm{ppm}$. When oil recovery was ceased, the injected brine was changed to $50 \%$ UER brine $(80,000 \mathrm{ppm})$ and $4.06 \%$ of OOIP additional oil was recovered. Again, as oil at the outlet stops to flow, the injected brine was switched to UER of 5,000 ppm and $7.6 \%$ of OIP additional oil was recovered. Finally, changing injection water salinity to UER of $1,000 \mathrm{ppm}$ produced additional incremental oil recovery of $4.9 \%$ of OOIP. These results are similar to the results obtained by Yousef et al. (2011). The results of the DSF experiment indicated that a significant improvement of oil recovery was obtained by injection of different salinity waters in a descending order. Figure 6 presents a comparison between continuous high-salinity and continuous low-salinity injection with DSF using CCs of similar average permeability $21 \mathrm{md}$ and porosity of $24 \%$.

The results presented in Fig. 6 clearly demonstrate that for secondary flooding mode, i.e. Injection at connate water saturation, UER brine diluted to $5,000 \mathrm{ppm}$ is superior to DSF. While, for tertiary flooding mode, it is recommended to apply DSF instead of continuous low-salinity flooding.

\section{Impact of core length on the performance of low- salinity water injection and CO2-WAG process}

To study the effect of core length on the displacement efficiency of brine injection and $\mathrm{CO}_{2} \mathrm{WAG}$, single and $\mathrm{CC}$ experiments were conducted using cores obtained from well BU 589 with similar average permeability of $20 \mathrm{md}$. The selected average permeability represents the average permeability of the candidate reservoir. Low- and highsalinity floods were conducted using single core and CC samples. Water salinity was varied from 197,357 to $1,000 \mathrm{ppm}$ using UER brine. Results indicated that core length had no significant effect on the displacement efficiency of low salinity flooding except in the case of the optimum salinity system UER 5,000 ppm salinity. The displacement efficiency of low-salinity single and CCs are 84 and $71 \%$ of the OOIP, respectively, as shown in Fig. 7. This observation may be attributed to the fact that secondary flood generates a reasonable oil bank that could be maintained throughout the flooding process.

High-salinity (171,585 ppm) $\mathrm{CO}_{2}$ WAG flooding experiments were also conducted using single core $(10 \mathrm{~cm})$ and $\mathrm{CC}$ samples $(33 \mathrm{~cm})$. The $\mathrm{CO}_{2} \mathrm{WAG}$ ratio of 1:1, 2:1, and 1:2 were employed in this task. The entire $\mathrm{CC}$ samples used in this study have similar average permeability of $20 \mathrm{md}$. The 
Fig. 4 Oil recovery versus pore volume injected LSWF, HSWF, CCI SC

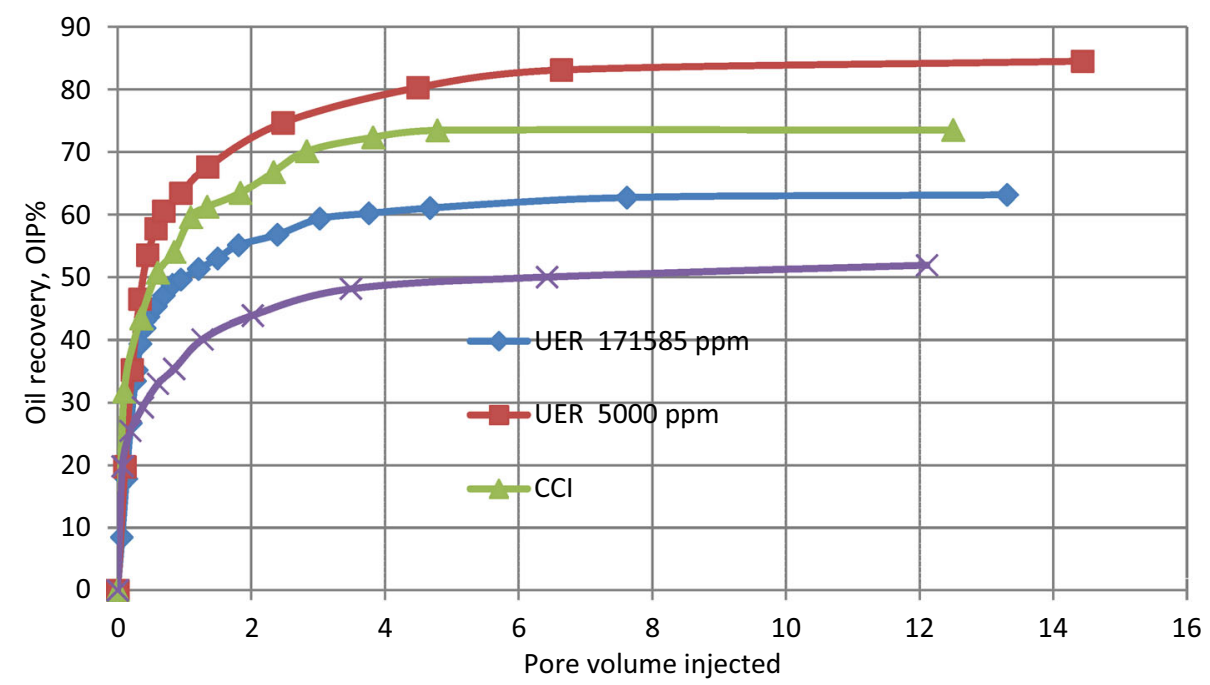

High- and low-salinity CO2-WAG performance

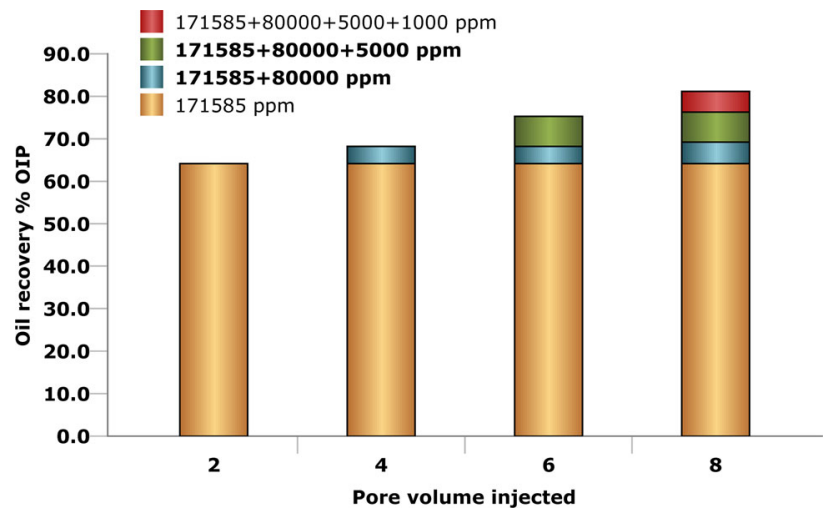

Fig. 5 Oil recovery for degraded salinity flooding

experimental runs involved injecting $\mathrm{CO}_{2}$ in alternating two cycles with high salinity water into oil saturated core at irreducible water saturation, each at a constant injection rate of $1 \mathrm{cc} / \mathrm{sec}$, until ultimate recovery is reached. Figure 8 presents the results of the runs in terms of the displacement efficiency versus $\mathrm{CO}_{2}$ WAG ratio and it can be noticed that for the designed $\mathrm{CO} 2-\mathrm{WAG}$ ratios, the displacement efficiency increases with increasing core length.

The results of these different $\mathrm{CO} 2-\mathrm{WAG}$ ratios indicate that displacement efficiency increased with increasing the core length. Miscibility conditions were achieved in all composite $\mathrm{CO} 2-\mathrm{WAG}$ ratio experiments as the displacement efficiency reached $90-98 \%$ before breakthrough. The low ultimate oil recovery observed during single core CO2-WAG flooding experiments may be attributed to the lack of achievement of miscibility conditions before breakthrough. Therefore, miscible CO2-WAG process requires a specific core length to insure reaching miscibility before breakthrough in order to obtain reliable results and thus the core length is a critical parameter in conducting $\mathrm{CO} 2-\mathrm{WAG}$ flooding experiments.
As part of a quick screening process of the effect of injection water salinity on the WAG flooding experiments SC floods were conducted using the same design $\mathrm{CO} 2-\mathrm{WAG}$ ratios: 1:1, 2:1, and 1:2. A $20 \% \mathrm{PV}$ of $\mathrm{CO}_{2}$ was employed in the development of two WAG cycles schemes. Figure 9 presents a comparison of the performance of low and high salinity during different $\mathrm{CO} 2-\mathrm{WAG}$ schemes. Results indicate that injection water salinity have a significant effect on the performance of CO2-WAG flooding except for the 1:1 WAG process. Figure 9 also shows that 1:2 low-salinity CO2-WAG process enhances the oil recovery by more than $28 \%$ OOIP over 1:2 high-salinity CO2-WAG process.

A CO2-WAG ratio of 1:2 is considered as the optimum system in this case due to the need to a higher $\mathrm{CO}_{2} /$ water ratio during each cycle in the case of $\mathrm{SC} \mathrm{CO} 2-\mathrm{WAG}$ floods as the system approaches miscibility as explained above in the core length effect section. The oil recovery factor was found to increase by about $20 \%$ of the OOIP in low salinity WAG 1:2 as compared to high salinity WAG 1:2 which are in line with the results obtained by Dang et al. (2013). High salinity $\mathrm{CO} 2-\mathrm{WAG}$ flooding experiments, using $\mathrm{CC}(33 \mathrm{~cm}$ long) and $20 \%$ of $\mathrm{PV}$ of $\mathrm{CO}_{2}$ divided into two cycles for different $\mathrm{CO} 2-\mathrm{WAG}$ ratios of $1: 1,2: 1$, and $1: 2$ at reservoir pressure of $3,200 \mathrm{psia}$ and $250^{\circ} \mathrm{F}$ were conducted first. Figure 10 shows the effect of injection brine salinity on the displacement efficiency for $\mathrm{CC}$ high salinity $\mathrm{CO} 2-\mathrm{WAG}$ flooding. As WAG ratio was changed from 1:1 to 2:1, the displacement efficiency was increased from $88 \%$ OOIP to $98 \%$ OOIP. In the long core experiments, multi-contact miscibility was achieved before the breakthrough and $\mathrm{CO}_{2}$ miscible displacement is the dominant mechanism. Results indicates that WAG ratio's have a significant effect on the performance of CO2-WAG flooding, and the optimum WAG ratio is $2: 1$ in the case of $\mathrm{CC}$ system which is 
Fig. 6 Comparison of oil recovery for different salinity systems

Fig. 7 Displacement efficiency of high and low salinity water floods for SC and CC

Fig. 8 Displacement efficiency of different $\mathrm{CO}_{2}$ WAG floods for $\mathrm{SC}$ and $\mathrm{CC}$

Fig. 9 The effect of water salinity on the single core $\mathrm{CO} 2$ WAG process
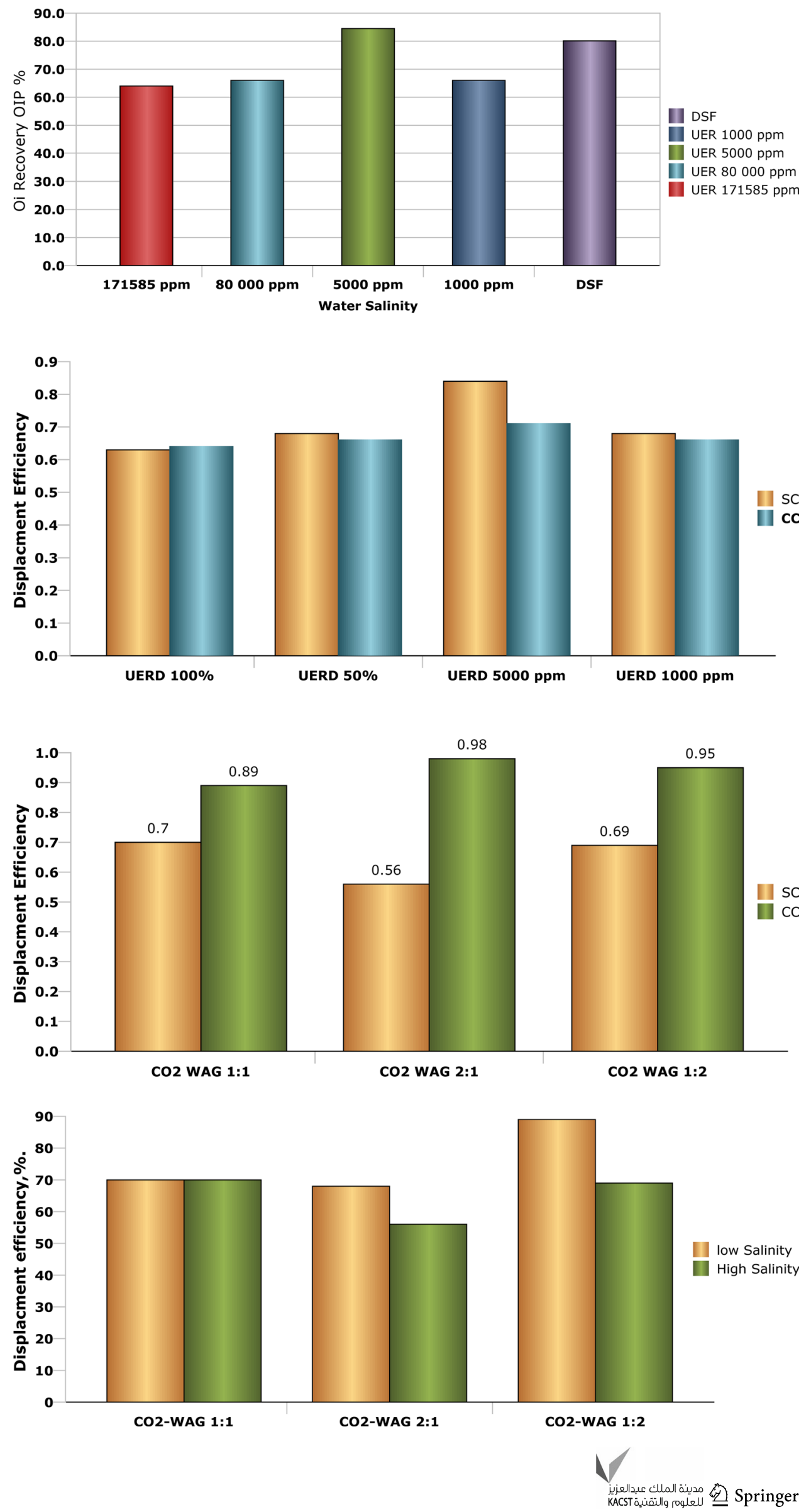
Fig. 10 High salinity WAG Composite core

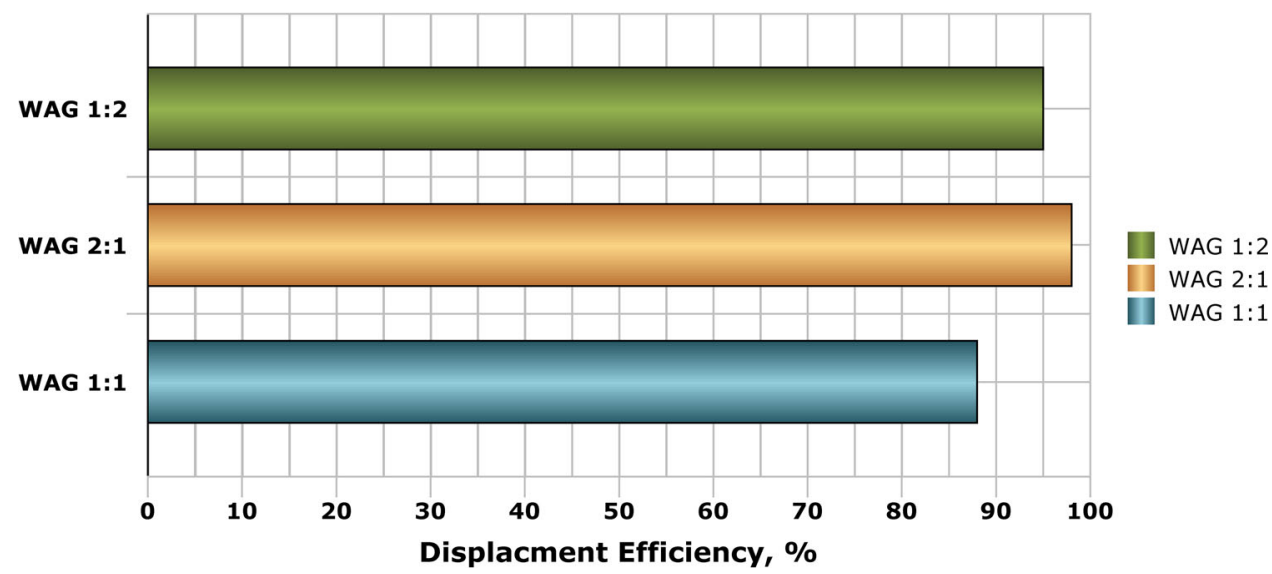

Fig. 11 Oil recovery $(\%)$ of produced oil versus $\mathrm{CO}_{2}$ cycles, HSCC WAG 1:1

Fig. 12 Oil recovery $(\%)$ of produced oil versus $\mathrm{CO}_{2}$ cycles, HSCC WAG 1:2
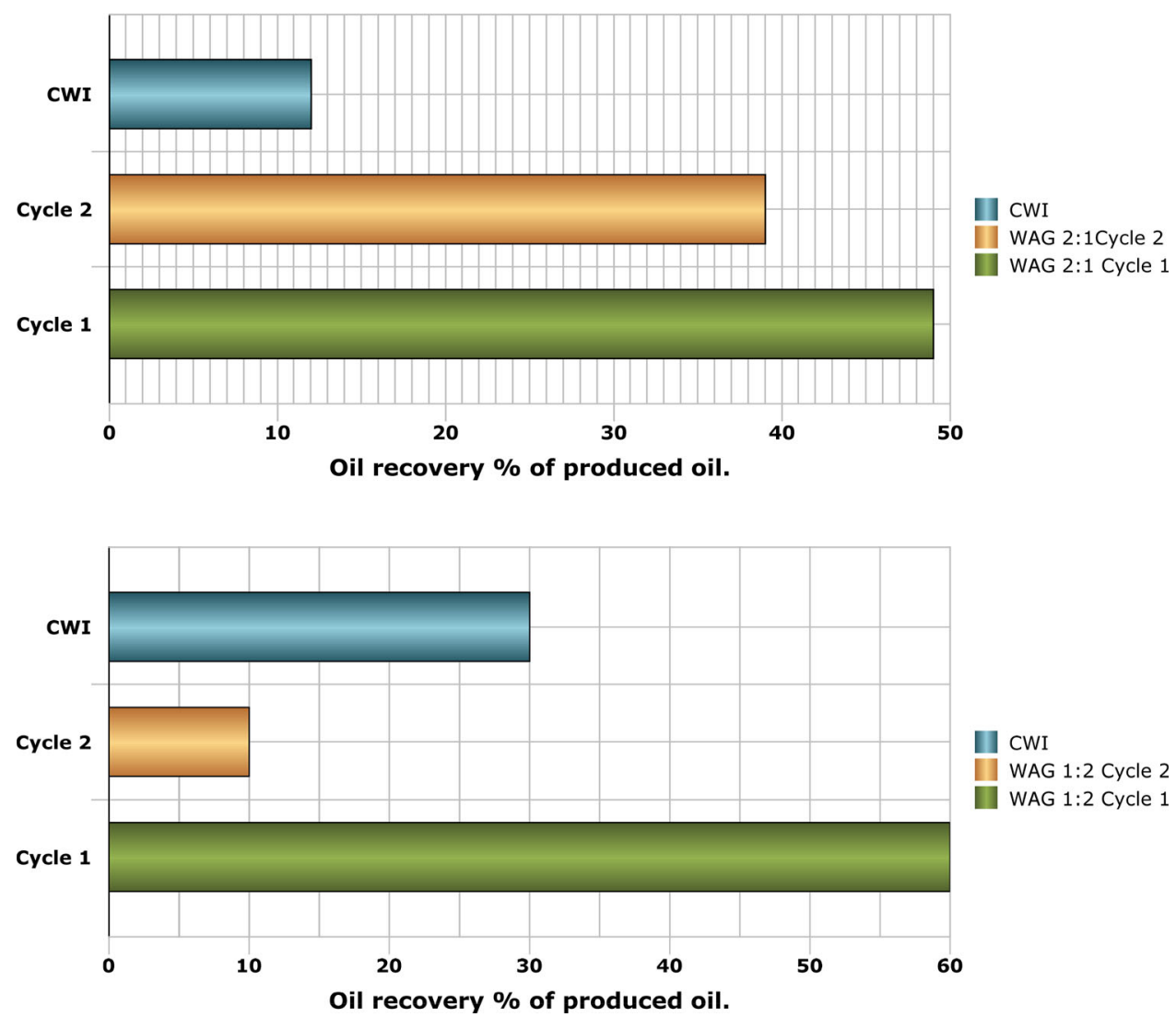

attributed to lower pore volume contacted by the $\mathrm{CO}_{2}$ in the cases of WAG's 1:1 and 1:2 as compared to WAG 2:1. No runs were conducted for low-salinity $\mathrm{CC}$ CO2-WAG because high displacement efficiencies were obtained using of high salinity and no significant oil recovery was expected especially in the case of WAG 2:1 (98\%). The performance of CO2-WAG during different stages of process, i.e., different cycles, is an important factor that may affects the economics of the selected system which is usually ignored by many researchers. Producing most of the producible oil at early stage of the process makes a significant impact of the present value and the project rate of return. Figures 11,
12 , and 13 present plots of oil recovery (\% of produced oil during different stages of the flood) versus cycle number for WAG's 1:1, 2:1, and 1:2. As mentioned before, two cycles and a fixed volume of $\mathrm{CO}_{2}(20 \% \mathrm{PV})$ were used in all runs. As shown in Fig. 11, 57, 23, and $20 \%$ of producible oil were produced during cycle 1 , cycle 2 , and continuous water injection, respectively for $\mathrm{CO} 2-\mathrm{WAG} 1: 1$. On the other hand for the optimum system CO2-WAG 2:1, 49, 39, and $12 \%$ of producible oil were produced during cycle 1 , cycle 2 , and continuous water injection, respectively as shown in Fig. 13. In general, decreasing the water-CO 2 ratio during the high salinity $\mathrm{CC}$ WAG flood seems to 
Fig. 13 Oil recovery $(\%)$ of produced oil versus $\mathrm{CO}_{2}$ cycles, HSCC WAG 2:1

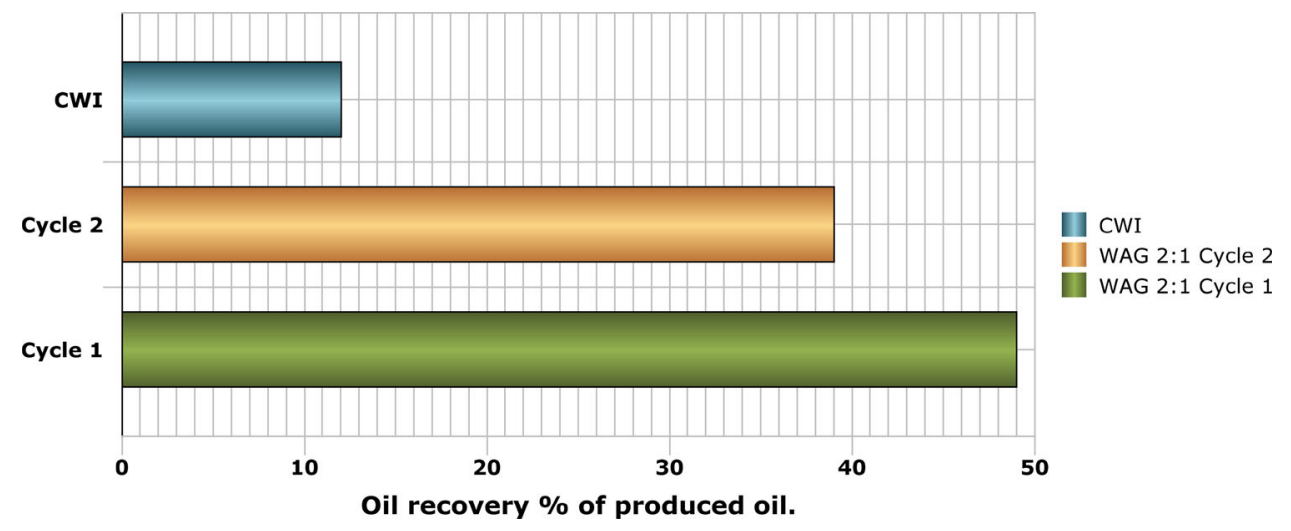

accelerate the oil production and increasing water- $\mathrm{CO}_{2}$ WAG ration increases the ultimate oil recovery.

\section{Conclusions}

Based on the results of this work the following conclusions may be drawan:

1. Decreasing the water- $\mathrm{CO}_{2}$ ratio during the $\mathrm{HS} \mathrm{CC}$ WAG flood accelerates the oil production and increasing water- $\mathrm{CO}_{2} \mathrm{WAG}$ ratio increases the ultimate oil recovery.

2. For the studied system, no significant additional oil recovery could be obtained by using low-salinity $\mathrm{CO}_{2}$ miscible WAG flooding.

3. Significant improvement in oil recovery was observed during low-salinity $\mathrm{CO}_{2}$ near miscible WAG flooding compared to high salinity $\mathrm{CO} 2-\mathrm{WAG}$ for the optimum WAG system.

4. Core length is a critical parameter in the design of CO2-WAG flooding experiments.

Acknowledgments The authors would like to express their appreciation for the financial support received from ADNOC and ADCO operating oil companies. Acknowledgment is extended to ADNOC R\&D OSC EOGR Technical Committee for their technical support. Special thank to Dr. Shahin Negahban for his fruitful discussion during different phases of the project. Also we would like to acknowledge the faculty of Engineering and Research Affairs at UAEU for their continuous support and encouragements.

Open Access This article is distributed under the terms of the Creative Commons Attribution License which permits any use, distribution, and reproduction in any medium, provided the original author(s) and the source are credited.

\section{References}

Abrams A (1975) The influence of fluid viscosity, interfacial tension, and flow velocity on residual oil saturation left by waterflood. SPE J 15(5):437-447
Aguilera ME, de Ramos AL (2004) Effect of $\mathrm{CO}_{2}$ diffusion on wettability for hydrocarbon-water- $\mathrm{CO}_{2}$ systems in capillaries. Int Commun Heat Mass Transf 31(8):1115-1122

Aleidan A, Mamora DD (2010) $\mathrm{SWACO}_{2}$ and $\mathrm{WACO}_{2}$ efficiency improvement in carbonate cores by lowering water salinity. Paper SPE 137548 presented at the Canadian Unconventional Resources \& International Petroleum Conference held in Calgary, Alberta, Canada

Caudle BH, Dyes AB (1958) Improving miscible displacement by gas-water injection. Pet Trans AIME 213:281-284

Christensen JR, Stenby EH, Skauge A (1998) Review of the WAG field experience. Paper SPE 71203 presented at the 1998 SPE International petroleum conference and exhibition of Mexico, Villahermosa

Craig Jr. FF, Geffen TM, Morse RA (1955) Oil recovery performance of pattern gas or water injection operations from model tests. Society of Petroleum Engineers, pp 7-15

Dang CT, Nghiem LX, Chen Z, Nguyen QP, Nguyen TB (2013) State-of-the art low salinity waterflooding for enhanced oil recovery. Paper SPE 165903 presented at the SPE Asia Pacific Oil \& Gas Conference and Exhibition, Jakarta, Indonesia

Fredi I. Stalkup (1992) Miscible displacement. SPE Monograph Volume 8, Richardson

Hinderaker L, Utseth RH, Hustad OS, Kvanvik BA, Paulsen JE (1996) A comprehensive Norwegian R\&D program on IOR. Paper SPE 36844 presented at the SPE European Petroleum Conference, Milan, Italy

Jackson DD, Andrews GL, Claridge EL (1985) Optimum WAG ratio versus rock wettability in $\mathrm{CO}_{2}$ flooding. Paper SPE 14303 presented at 60th Annual technical conference and exhibition of the Society of Petroleum engineers, Las Vegas, NV, USA

Jiang H, Nuryaningsih L, Adidharma H (2010) The effect of salinity of injection brine on water alternating gas performance in tertiary miscible carbon dioxide flooding: experimental study. Paper SPE 132369, presented at the SPE Western Regional Meeting held in Anaheim, CA, USA

Kulkarni MH, Rao DN (2005) Experimental investigation of miscible secondary gas injection. Paper SPE 95975 presented at SPE Annual Technical Conference and Exhibition, Dallas, TX

Rogers JD, Grigg RB (2000) A literature analysis of the WAG injectivity abnormalities in the $\mathrm{CO}_{2}$ process. Paper SPE 59329 presented at the 2000 review SPE/DOE Improved Oil Recovery symposium, Tulsa, OKlhoma

Yousef AA, Al-Saleh S, Al-Kaabi A, Al-Jawfi M (2011) Laboratory investigation of the impact of injection-water salinity and ionic content on oil recovery from carbonate reservoirs. SPE Reservoir Eval Eng 14:578-593

Zekri AY, Natuh AA (1992) Laboratory study on the effects of miscible WAG process on tertiary oil recovery. Paper SPE 24481 Presented at the 5th Abu Dhabi petroleum conference, Abu Dhabi, UAE

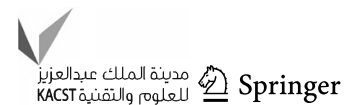

